\title{
Safety and outcomes of performing laparoscopic Roux-en-Y gastric bypass and sleeve gastrectomy at an ambulatory site of a tertiary care hospital in Ontario
}

\author{
Shaidah Deghan Manshadi, \\ MSc, MD \\ Kooroush Dehghan, MD \\ David I. Robertson, MD \\ Cara Reimer, MD, MSc \\ Boris Zevin, MD, PhD
}

Presented as a podium presentation at the Canadian Surgery Forum, Montréal, Que., Sept. 5-7, 2019.

Accepted Feb. 4, 2021

\section{Correspondence to:}

B. Zevin

Department of Surgery

Kingston General Hospital

76 Stuart St

Kingston ON K7L 2V7

boris.a.zevin@gmail.com

Cite as: Can J Surg 2022 January 18; 65(1). doi: $10.1503 /$ cjs. 007120

\begin{abstract}
Background: In Ontario, bariatric surgery is publicly funded and is performed only in accredited tertiary care hospitals. The purpose of our study was to report on the safety and outcomes of performing bariatric surgery at an ambulatory site of a tertiary care hospital in southern Ontario.
\end{abstract}

Methods: We conducted a retrospective cohort study of all adult (age $\geq 18 \mathrm{yr}$ ) patients who underwent primary laparoscopic Roux-en-Y gastric bypass (LRYGB) or laparoscopic sleeve gastrectomy (LSG) at the ambulatory site of our tertiary care hospital between September 2016 and August 2018. The 2 sites are $1.4 \mathrm{~km}$ apart. Patient demographic characteristics, duration of surgery, intraoperative and 90-day postoperative complications, number of transfers and readmission to the tertiary care hospital, and emergency department visits were collected.

Results: A total of 314 patients (285 women [90.8\%] and 29 men [9.2\%] with a mean age of $41.8 \mathrm{yr}$ [standard deviation (SD) $8.9 \mathrm{yr}$ ]) underwent surgery: LRYGB in 295 cases $(93.9 \%)$ and LSG in $19(6.0 \%)$. The mean body mass index was 45.3 (SD 5.1), the median American Society of Anesthesiologists score was 3 (range 2-4), and the median Edmonton Obesity Staging System score was 2 (range 0-4). The mean operative time was 119.8 (SD 23.1) minutes for LRYGB and 96.2 (SD 22.0) minutes for LSG, and the mean length of stay was 2.1 (SD 0.6) days and 2.1 (SD 0.2) days, respectively. Thirteen patients $(4.1 \%)$ required transfer to the tertiary care hospital for a postoperative complication. Of 312 patients, $29(9.3 \%)$ presented to emergency department within 90 days after surgery, and $8(2.6 \%)$ required readmission to hospital; no deaths were reported.

Conclusion: The findings suggest that LRYGB and LSG can be performed safely at an ambulatory site of a tertiary care hospital. However, caution should be exercised in performing these procedures at an ambulatory site without a tertiary care hospital affiliation, as patients may require urgent transfer for a serious postoperative complication.

Contexte : En Ontario, la chirurgie bariatrique est couverte par le régime public et n'est effectuée que dans des hôpitaux de soins tertiaires agréés. Le but de notre étude était de faire le point sur l'innocuité et l'issue des chirurgies bariatriques effectuées au site de soins ambulatoires d'un hôpital de soins tertiaires du Sud de l'Ontario.

Méthodes : Nous avons procédé à une étude rétrospective sur tous les patients adultes ( $\geq 18$ ans) ayant subi une dérivation gastrique Roux-en-Y primaire par laparoscopie ou une gastrectomie en manchon par laparoscopie au site de soins ambulatoires de notre hôpital de soins tertiaires entre septembre 2016 et août 2018. Le site de soins ambulatoires et le centre de soins tertiaires sont à $1,4 \mathrm{~km}$ de distance l'un de l'autre. Les caractéristiques démographiques des patients, la durée de la chirurgie, les complications peropératoires et dans les 90 jours postopératoires et le nombre de transferts et de réadmissions au centre de soins tertiaires et de consultations aux urgences ont été recueillis.

Résultats : En tout, 314 patients (285 femmes [90,8\%] et 29 hommes [9,2\%] âgés en moyenne de 41,8 ans [écart-type (É.-T.) 8,9 ans]) ont subi une chirurgie : dérivation dans 295 cas $(93,9 \%)$ et gastrectomie dans 19 cas $(6,0 \%)$. L'indice de masse corporelle moyen était de 45,3 (É.-T. 5.1), le score médian de l'American Society of Anesthesiologists était de 3 (éventail 2-4) et le score médian de l'Edmonton Obesity Staging System score était de 2 (éventail 0-4). Le temps opératoire moyen a été de 119,8 (E.-T. 23,1) minutes pour la dérivation et de 96,2 (É.-T. 22,0) minutes pour la gastrectomie, et la durée moyenne du séjour a été de 2,1 (É.-T. 0,6 ) jours et de 2,1 (É.-T. 0,2$)$ jours, respectivement. Treize patients $(4,1 \%)$ ont dû être transférés à 
l'hôpital de soins tertiaires pour une complication postopératoire. Sur 312 patients, 29 $(9,3 \%)$ ont consulté aux urgences dans les 90 jours suivant leur chirurgie et $8(2,6 \%)$ ont dû être réhospitalisés; aucun décès n'a été signalé.

Conclusion : Selon nos observations, la dérivation Roux-en-Y et la gastrectomie en manchon peuvent être effectuées sans danger au site de soins ambulatoires d'un hôpital de soins tertiaires. Par contre, la prudence est de mise si de telles interventions sont réalisées dans un site de soins ambulatoires qui ne serait pas affilié à un centre de soins tertiaires étant donné que les patients pourraient avoir besoin d'un transfert urgent pour une grave complication postopératoire.

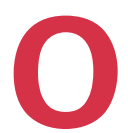

besity is a chronic disease associated with severe comorbidities that entails a reduced quality of life, increased health care costs and reduced life expectancy. ${ }^{1,2}$ In 2018, an estimated 7.3 million Canadian adults had class I obesity or greater (body mass index [BMI] $\geq 30.0$ ), a figure that has been increasing steadily over time. ${ }^{3}$ More worrisome are the continued increases seen in the prevalence of class II (BMI 35.0-39.9) and class III (BMI $\geq 40.0$ ) obesity in Canada, from 1.207 million people in 2009 to 1.774 million in $2017 .{ }^{3}$ In Canada, there are regional variations in the rates of obesity, with Ontario reporting $26.1 \%$ of the population with class I obesity or higher in 2018.,5

Bariatric surgery provides durable, long-term weight loss and amelioration of obesity-related comorbidities. ${ }^{6} \mathrm{It}$ is currently available in most provinces across Canada. However, regional volumes vary considerably, which leads to considerable disparities between provinces. ${ }^{3}$ In Ontario, all publicly funded bariatric operations are performed at Bariatric Centres of Excellence accredited by the Ontario Bariatric Network. At a minimum, accreditation requires 1) a full acute care and inpatient facility; 2) intensive care unit availability; 3) 24-hour emergency department and surgical coverage; 4) oximetry beds for postoperative care, with availability of a respiratory technician; 5) at least 2 laparoscopic bariatric surgeons, with each surgeon performing a minimum of 50 cases per year; 6) a minimum volume of 120 bariatric cases per year; 7) a multidisciplinary clinic for preoperative and postoperative care; $8)$ medical bariatric support for clinic and inpatient care; and 9) psychiatry support for pre- and postoperative assessment if necessary. As such, all publicly funded bariatric surgery in Ontario is performed at tertiary care hospitals. Performing bariatric surgery in patients at low or intermediate risk at ambulatory sites of tertiary care hospitals may create additional capacity within the health care system to increase the annual number of bariatric operations performed in Canada. ${ }^{7}$ However, the safety of this health care delivery model has yet to be extensively investigated.

The purpose of the present study was to report on patients' outcomes, morbidity and use of health care services after laparoscopic Roux-en-Y gastric bypass (LRYGB) and laparoscopic sleeve gastrectomy (LSG) performed at the ambulatory site of a tertiary care hospital in Ontario.

\section{Methods}

\section{Study setting and design}

In 2016, the bariatric surgery program at the Kingston Health Sciences Centre (Kingston, Ontario, Canada) was accredited to perform bariatric surgery at both a tertiary care hospital and an ambulatory site of the tertiary care hospital. The 2 sites are $1.4 \mathrm{~km}$ apart. The ambulatory site is open from Monday to Friday, and patients undergoing bariatric surgery can stay for up to 48 hours at the ambulatory site. As there is no after-hours access to imaging, operating rooms, intensive care unit or medical consultation services at the ambulatory site, the Kingston Health Sciences Centre designed a strict protocol to facilitate urgent transfer to the tertiary care hospital for postoperative complications.

Our program has 2 surgeons, 1 fellowship-trained bariatric surgeon (B.Z.) and 1 experienced minimally invasive general surgeon without bariatric fellowship training (D.I.R.). The second surgeon was proctored by the fellowship-trained bariatric surgeon during the first 50 bariatric cases to ensure that he had passed the initial learning curve. ${ }^{8}$ Surgery residents, bariatric surgery fellows and anesthesia residents participate in the LRYGB and LSG cases performed at the ambulatory site. A selected group of anesthesiologists and nurses who have a special interest in bariatric surgery cases provide the majority of perioperative and intraoperative care.

We conducted a retrospective cohort study of all adult (age $\geq 18 \mathrm{yr}$ ) patients who underwent LRYGB or LSG at the ambulatory site of the tertiary care hospital between Sept. 1, 2016, and Aug. 31, 2018. Ethics approval was obtained from Queen's University Health Sciences and Affiliated Teaching Hospitals Research Ethics Board (SURG-452-18).

\section{Inclusion and exclusion criteria}

Patients with the following characteristics were not eligible to undergo surgery at the ambulatory site: age younger than 18 years; history of prior bariatric surgery, revision or conversion bariatric surgery; untreated obstructive sleep apnea; prior history of venous thromboembolism; Obesity Surgery Mortality Risk Score 4 or higher; or BMI greater than 55. 
Patients undergoing concurrent hiatus hernia repair, cholecystectomy, or ventral or umbilical hernia repair were included in our cohort.

\section{Operative technique}

We perform LRYGB as an antecolic, antegastric configuration with a $50-100 \mathrm{~cm}$ biliopancreatic limb, a 100-150 cm Roux limb and a $25 \mathrm{~mm}$ circular stapled gastrojejunal anastomosis. We routinely close jejunojejunostomy mesenteric defects and Petersen's space, and perform intraoperative gastroscopy for an air leak test of the gastrojejunal anastomosis.

We perform LSG using a $40 \mathrm{~F}$ bougie to size the sleeve and perform routine intraoperative gastroscopy for an air leak test.

\section{Perioperative care}

Patients receive multimodal analgesia perioperatively, including oral celecoxib and acetaminophen prophylaxis preoperatively, local analgesia injection into the subcutaneous tissues around port sites intraoperatively, and acetaminophen and hydromorphone elixir (as needed) for pain postoperatively. We administer triple prophylaxis for postoperative nausea and vomiting (dexamethasone, ondansetron and metoclopramide given intravenously) intraoperatively, followed by intravenous administration of metoclopramide every 8 hours for 3 doses. Nasogastric tubes and drains are not used, and patients are allowed to drink liquids and take oral medications starting 2 hours after the procedure.

Patients are assessed daily by the attending surgeon. Those whose postoperative course deviates from expected are reassessed by the attending surgeon, who ultimately makes the decision regarding transfer to the tertiary care hospital.

\section{Transfer criteria}

As per preprinted orders, surgeons are alerted by nursing staff if patients' vital signs fall outside of normal parameters or if patients experience an unusual postoperative course (e.g., increased pain, nausea or vomiting, abdominal distension, melena or hematemesis). In such cases, a surgeon assesses the patient and decides whether the patient should be transferred to the tertiary care hospital. Examples of indications for transfer include sustained sinus tachycardia, ongoing nausea and vomiting, gastrointestinal bleeding, hypoxemia requiring supplemental oxygen on the day of planned discharge, severe abdominal pain and postoperative bleeding. Given the newness of our program, we had a fairly low threshold to transfer patients to the tertiary care hospital.

\section{Demographic data}

We collected the following patient demographic data from the patients' electronic medical records: age, sex, preoperative BMI, American Society of Anesthesiologists score, Edmonton Obesity Staging System score, prior abdominal surgery and obesity-related comorbidities.

\section{Outcomes}

Outcomes of interest included duration of surgery (from start of anesthesia to end of anesthesia, in minutes), intraoperative complications, length of hospital stay (in days), requirement for transfer to the tertiary care centre, reasons for transfer and complications arising within the first 90 days after surgery. This information was obtained from the patients' electronic medical records. We also collected data on use of health care services, including emergency department visits and unscheduled visits to a family physician's office, within 90 days of surgery from postoperative visit follow-up forms and through review of our hospital electronic medical records.

\section{Statistical analysis}

We report descriptive statistics as mean and standard deviation (SD) for continuous variables, and median and range for categorical variables.

\section{Results}

A total of 314 patients underwent surgery between Sept. 1, 2016, and Aug. 31, 2018: 295 (93.9\%) underwent LRYGB, and $19(6.0 \%)$ underwent LSG. Baseline patient characteristics are shown in Table 1 . The majority of patients (285 [90.8\%]) were female.

Table 1. Baseline characteristics of patients who underwent LRYGB or LSG at the ambulatory site of a tertiary care hospital in Ontario between Sept. 1, 2016, and Aug. 31, 2018

\begin{tabular}{|c|c|}
\hline Characteristic & $\begin{array}{c}\text { No. (\%) of patients* } \\
n=314\end{array}$ \\
\hline Age, mean $\pm S D, y r$ & $41.8 \pm 8.9$ \\
\hline \multicolumn{2}{|l|}{ Sex } \\
\hline Female & $285(90.8)$ \\
\hline Male & $29(9.2)$ \\
\hline Body mass index, mean \pm SD & $45.3 \pm 5.1$ \\
\hline ASA score, median (range) & $3(2-4)$ \\
\hline \multicolumn{2}{|l|}{ Surgery } \\
\hline LRYGB & 295 (93.9) \\
\hline LSG & $19(6.0)$ \\
\hline EOSS score, median (range) & $2(0-4)$ \\
\hline \multicolumn{2}{|c|}{$\begin{array}{l}\text { ASA = American Society of Anesthesiologists; EOSS = Edmonton Obesity Severity } \\
\text { Score; LRYGB = laparoscopic Roux-en-Y gastric bypass; LSG = laparoscopic sleeve } \\
\text { gastrectomy; } S D=\text { standard deviation. } \\
{ }^{*} \text { Except where noted otherwise. }\end{array}$} \\
\hline
\end{tabular}


The most common obesity-related comorbidities were obstructive sleep apnea (230 patients [73.2\%]), musculoskeletal disease (165 [52.5\%]) and urinary incontinence (153 [48.7\%]) (Table 2), and the least common were cardiac disease (11 [3.5\%]), chronic obstructive pulmonary disease $(9[2.9 \%])$ and cerebral vascular accident (4 $[1.3 \%])$. The most common mental health and addiction comorbidities were history of depression (189 [60.2\%]), eating disorder (188 [59.9\%]), smoking (156 [49.7\%]) and anxiety (137 [43.6\%]).

The most common prior abdominal procedures were obstetric and gynecologic operations (149 [47.4\%]), cholecystectomy (77 [24.5\%]), appendectomy (31 [9.9\%]), ventral hernia repair $(5[1.6 \%]$ and bowel resection $(3[1.0 \%])$.

The mean operative time from induction of general anesthesia to extubation was 118.3 (SD 23.7) minutes for the entire cohort. The corresponding times for LRYGB and LSG were 119.8 (SD 23.1) minutes and 96.2 (SD

\begin{tabular}{|lc|}
\hline Table 2. Obesity-related comorbidities at baseline \\
\hline Comorbidity & No. $(\%)$ of patients \\
\hline Musculoskeletal disorder & $165(52.5)$ \\
\hline Cardiac disease & $11(3.5)$ \\
\hline Diabetes & $25(8.0)$ \\
\hline Cerebrovascular accident & $4(1.3)$ \\
\hline Dyslipidemia & $58(18.5)$ \\
\hline Gastresophageal reflux disease & $89(28.3)$ \\
\hline Polycystic ovarian syndrome & $42(13.4)$ \\
\hline Infertility & $34(10.8)$ \\
\hline Chronic obstructive pulmonary disease & $9(2.9)$ \\
\hline Asthma & $68(21.7)$ \\
\hline Obstructive sleep apnea & $230(73.2)$ \\
\hline Urinary incontinence & $153(48.7)$ \\
\hline Renal disease & $32(10.2)$ \\
\hline History of depression & $189(60.2)$ \\
\hline History of anxiety & $137(43.6)$ \\
\hline Prior history of smoking & $156(49.7)$ \\
\hline Prior history of eating disorder & $188(59.9)$ \\
\hline Prior history of excessive drinking & $55(17.5)$ \\
\hline
\end{tabular}

\begin{tabular}{|lc|}
\hline Table 3. Frequency of intraoperative complications & \\
\hline Complication & $\begin{array}{c}\text { No. (\%) of } \\
\text { patients }\end{array}$ \\
\hline Laceration to superior pole of spleen from traction injury & $2(0.6)$ \\
\hline Stapling of orogastric tube during creation of gastric pouch & $1(0.3)$ \\
\hline Superficial liver laceration & $1(0.3)$ \\
\hline $\begin{array}{l}\text { Misfiring of stapler necessitating revision of gastric fundus } \\
\text { and pouch }\end{array}$ & $1(0.3)$ \\
\hline Narrowing of jejunojejunostomy requiring revision & $1(0.3)$ \\
\hline $\begin{array}{l}\text { Diaphragm laceration from liver retractor requiring chest } \\
\text { tube placement }\end{array}$ & $1(0.3)$ \\
\hline Enterotomy requiring repair & $2(0.6)$ \\
\hline Capnothorax (left) & $1(0.3)$ \\
\hline Liver injury requiring wedge resection & $1(0.3)$ \\
\hline Total & $11(3.5)$ \\
\hline
\end{tabular}

22.0) minutes, respectively. The mean hospital stay was 2.1 (SD 0.5) days for the entire cohort; it was 2.1 (SD 0.6) days for patients who underwent LRYGB and 2.1 (SD 0.2) days for those who underwent LSG.

There were 11 intraoperative complications (3.5\%) (Table 3).

Thirteen patients $(4.1 \%)$ required transfer to the tertiary care hospital (Table 4). Their average age was 45.9 (SD 8.9) years, their average BMI was 46.9 (SD 4.8), and 5 patients $(38 \%)$ were male. There were no significant differences in age $(p=0.1)$ or BMI $(p=0.3)$ between patients who were transferred and those who were not; however, the proportion of male patients was significantly higher in the group that was transferred $(38 \%$ v. $9 \% ; p<0.01)$.

Intra- and postoperative complications that necessitated transfer to the tertiary care hospital are reported in Table 5. Five patients were taken back to the operating room for laparoscopic exploration. The findings included bleeding (in 2 patients) and complication at jejunojejunostomy ( 2 patients); in 1 case, the findings were negative. Five patients required supportive care, with blood transfusion in 3 patients and with supplemental oxygen in 2 . The remaining 3 patients required observation without additional medical intervention.

Two patients $(0.6 \%)$ were lost to follow-up in the first 30 days. Among the remaining 312 patients, there were 38 $(12.2 \%)$ unscheduled contacts with the health care system within 90 days of surgery. These included 29 (9.3\%) visits to the emergency department, 8 of which required hospital admission, and 1 visit to the family doctor.

Postoperative complications were seen in 26 of 312 patients $(8.3 \%)$ within 90 days after surgery; 8 (2.6\%) required readmission to hospital (Table 6 ). The most common complications were bleeding or hematoma (7 patients [2.2\%]) and, in 4 patients (1.3\%) each, wound infection, diarrhea and intestinal obstruction. No deaths were reported within 90 days of surgery.

\section{Discussion}

In this retrospective cohort study reviewing our 2-year experience of performing publicly funded bariatric surgery in patients at low or moderate risk at an ambulatory site of a tertiary care hospital, more than $90 \%$ of procedures were LRYGB, with some patients having a concurrent hiatus hernia repair or cholecystectomy or both. Intraoperative complications were seen in $3.5 \%$ of patients, and $4.1 \%$ of patients required transfer from the ambulatory site to the tertiary care hospital for a postoperative complication. Overall, $9.3 \%$ of patients presented to the emergency department within 90 days of surgery, and $2.6 \%$ required readmission to hospital.

These positive results provide important information to stakeholders, including bariatric surgeons, obesity specialists and policy-makers. By demonstrating safety and 
Table 4. Characteristics of patients who required transfer to tertiary care hospital

\begin{tabular}{|c|c|c|c|c|c|}
\hline Patient no. & Age, yr & Sex & $\begin{array}{l}\text { Body mass } \\
\text { index }\end{array}$ & Procedure & Obesity-related comorbidity \\
\hline 1 & 34 & Male & 41 & LRYGB & Obstructive sleep apnea, asthma, GERD \\
\hline 2 & 41 & Male & 46 & LSG & Obstructive sleep apnea, depression, chronic back pain \\
\hline 3 & 52 & Male & 47 & $\begin{array}{l}\text { LRYGB + umbilical } \\
\text { hernia repair }\end{array}$ & Hypertension, obstructive sleep apnea, migraines \\
\hline 4 & 59 & Female & 48 & LRYGB & $\begin{array}{l}\text { Type } 2 \text { diabetes, PCOS, osteoarthritis, obstructive sleep apnea, GERD, } \\
\text { urinary stress incontinence }\end{array}$ \\
\hline 5 & 38 & Female & 54 & LRYGB & GERD, hypothyroidism \\
\hline 6 & 51 & Female & 38 & $\begin{array}{l}\text { LRYGB + gastric wedge } \\
\text { resection }\end{array}$ & Hypertension, type 2 diabetes, obstructive sleep apnea, GERD, PCOS \\
\hline 7 & 55 & Female & 45 & $\begin{array}{l}\text { LRYGB + repair of } \\
\text { diaphragm perforation }\end{array}$ & $\begin{array}{l}\text { Osteoarthritis, obstructive sleep apnea, fatty liver, urinary stress } \\
\text { incontinence, migraines }\end{array}$ \\
\hline 8 & 35 & Female & 48 & LRYGB & Obstructive sleep apnea \\
\hline 9 & 50 & Male & 48 & LRYGB & $\begin{array}{l}\text { Hypertension, osteoarthritis, obstructive sleep apnea, asthma, migraines, } \\
\text { depression, hypothyroidism }\end{array}$ \\
\hline 10 & 47 & Female & 48 & LRYGB & Hypertension, venous stasis disease, urinary stress incontinence \\
\hline 11 & 50 & Female & 51 & $\begin{array}{l}\text { LRYGB + PEH + ventral } \\
\text { hernia repair }\end{array}$ & $\begin{array}{l}\text { Hypertension, type } 2 \text { diabetes, osteoarthritis, obstructive sleep apnea, } \\
\text { GERD, fatty liver, urinary stress incontinence }\end{array}$ \\
\hline 12 & 30 & Female & 42 & LRYGB & $\begin{array}{l}\text { Obstructive sleep apnea, venous stasis disease, fatty liver, urinary stress } \\
\text { incontinence }\end{array}$ \\
\hline 13 & 41 & Male & 53 & LRYGB & Dyslipidemia, obstructive sleep apnea, asthma \\
\hline
\end{tabular}

Table 5. Frequency of intra- and postoperative complications requiring transfer to tertiary care hospital

\begin{tabular}{|lc|}
\hline Complication & $\begin{array}{c}\text { No. (\%) of } \\
\text { patients }\end{array}$ \\
\hline Nonresolving sinus tachycardia & $1(0.3)$ \\
\hline Obstruction at jejunojejunostomy anastomosis & $1(0.3)$ \\
\hline Nonresolving nausea and vomiting & $1(0.3)$ \\
\hline Port site bleed & $1(0.3)$ \\
\hline Anemia concerning for postoperative bleeding* & $5(1.6)$ \\
\hline Diaphragm laceration requiring chest tube placement & $1(0.3)$ \\
\hline Hypoxia & $1(0.3)$ \\
\hline Abdominal distension not yet diagnosed & $1(0.3)$ \\
\hline Ileus & $1(0.3)$ \\
\hline Total & $13(4.1)$ \\
\hline *Postoperative drop in hemoglobin level of 30 points or more. & \\
\hline
\end{tabular}

Table 6. Frequency of postoperative complications within 90 days of surgery

\begin{tabular}{|lc|}
\hline Complication & $\begin{array}{c}\text { No. (\%) of patients } \\
n=312^{*}\end{array}$ \\
\hline Bowel obstruction & $4(1.3)$ \\
\hline Incisional hernia & $1(0.3)$ \\
\hline Internal hernia & $1(0.3)$ \\
\hline Wound infection & $4(1.3)$ \\
\hline Gastrojejunal anastomotic stenosis/stricture & $2(0.6)$ \\
\hline Acute kidney injury & $3(1.0)$ \\
\hline Bleeding/hematoma & $7(2.2)$ \\
\hline Persistent diarrhea & $4(1.3)$ \\
\hline Total & $26(8.3)$ \\
\hline *Two patients were lost to follow-up. & \\
\hline
\end{tabular}

effectiveness, this ambulatory bariatric surgery model may create additional capacity for bariatric surgery in Canada. As well, the model may help to reduce regional disparities in access to bariatric surgery across Canada. ${ }^{3,9,10}$

The safety of performing LRYGB, LSG and laparoscopic adjustable gastric banding in a secondary health care centre in Quebec was reported by Christou in 2013. He described 676 publicly funded cases (558 LRYGB, 29 LSG and 89 gastric band) performed in a 17-bed private hospital in Montréal with a dedicated "service corridor" to a tertiary care hospital. The reported 30-day complication rate was $7.5 \%$, and $1.2 \%$ of patients required transfer to a tertiary care hospital. Our 90 -day postoperative complication rate, $8.3 \%$, is similar to that reported by Christou, ${ }^{7}$ but our transfer rate, $4.1 \%$, appears to be higher. This may be explained by the higher proportion of LRYGB cases performed at our institution, which are often associated with a higher perioperative complication rate compared to LSG or adjustable gastric banding. ${ }^{11}$ In addition, the threshold to transfer may have differed between the centres.

Our practice is to discharge patients after LRYGB or LSG on postoperative day 1 or 2. This is in agreement with an analysis of data from the Bariatric Outcomes Longitudinal Database, which showed an increased risk of 30-day mortality and serious complications in patients undergoing LRYGB with lengths of stay shorter than 23 hours. ${ }^{12}$ It is also in agreement with analyses of the Metabolic and Bariatric Surgery Accreditation and Quality Improvement Program national database, which showed increased morbidity and mortality for same-day discharge for $\mathrm{LSG}^{13}$ and LRYGB. ${ }^{14}$ 
There are several advantages to performing bariatric surgery in ambulatory sites of tertiary care hospitals. The cost of performing surgery in an ambulatory site has been reported to be lower than performing the same surgery in a tertiary care hospital for complex lower extremity orthopedic surgery, ${ }^{15}$ cervical discectomy ${ }^{16}$ and surgical reversal of sterilization (microsurgical tubal anastomosis). ${ }^{17} \mathrm{We}$ hypothesize that the cost of performing bariatric surgery in an ambulatory site may be lower than that in a tertiary hospital; however, further research with appropriate matching of patient characteristics and case difficulty is required to confirm this hypothesis.

Operating room efficiency at an ambulatory site is often higher than at a tertiary care hospital. In our institution, this difference in efficiency translates into 1 fewer bariatric surgery case completed per day at the tertiary care hospital versus the ambulatory site. Similar results regarding operating room efficiency have been reported in the urology ${ }^{18}$ and anesthesia ${ }^{19}$ literature. $\mathrm{Xu}$ and colleagues ${ }^{18}$ examined $^{2}$ ureteroscopy procedures performed by a single surgeon at an ambulatory centre versus a tertiary care academic medical centre for patients assessed as American Society of Anesthesiologists class 1 or 2. The authors controlled for patient, case complexity and case order characteristics. They used multiple linear regressions to evaluate differences in total, preoperative, operative and postoperative times, delays and operating room turnaround times between the 2 facilities and found consistently shorter mean times at the ambulatory centre than at the tertiary care centre.

Some of the operating room efficiencies observed at an ambulatory site may be due to lack of trainees for both the surgery team and the anesthesia team. Urman and colleagues ${ }^{19}$ compared day surgery operating room efficiency for anesthesiologists working alone and those working with residents to determine whether trainees affect operating room efficiency significantly. They showed that, compared to the solo anesthesiologist group, anesthesiologists working with residents had significantly longer induction, emergence and total anesthesia-controlled times.

We plan to further investigate which factors contribute to the improved operating room efficiencies for bariatric surgery performed at the ambulatory site as compared to the tertiary care hospital.

\section{Limitations}

The proportion of patients presenting for unscheduled visits to the emergency department or their family doctor within 90 days of surgery may be an underestimation of the true proportion, as there is the potential for recall bias when patients report these events. We attempted to mitigate this bias by examining our hospital's electronic medical record for all patients in our cohort to document visits to the emergency department. However, the bariatric program's large catchment area limited the ability to capture all possible emergency visits.

Our rates of peri- and postoperative complications represent data for the first 2 years of the bariatric surgery program at our institution. Although our complication rates are in agreement with published rates from the United States ${ }^{20}$ and Canada, ${ }^{21}$ we would expect a reduction in rates as the program and surgeon experience continue to mature. ${ }^{22}$

The operative times reported in our study include concurrent procedures (hiatus hernia repair, cholecystectomy, umbilical hernia repair) that were done in conjunction with the primary bariatric surgery. As such, the mean operative times for primary LRYGB and LSG without a concurrent operation are expected to be shorter than our reported times.

Finally, our results may not be generalizable to other bariatric programs, with different distances and traffic patterns between the tertiary care hospital and its ambulatory site. Our 2 hospital sites are $1.4 \mathrm{~km}$ apart, with minimal traffic along the transfer route at any time of day. As such, our results may not be applicable to programs with greater distances between hospitals and longer transfer times.

\section{Conclusion}

Laparoscopic Roux-en-Y gastric bypass and LSG can be performed safely in patients at low to moderate risk at an ambulatory site of a tertiary care hospital with an overnight stay. However, caution should be exercised in performing these procedures at an ambulatory site without a tertiary care hospital affiliation, as patients may require urgent transfer for a serious postoperative complication.

Affiliations: From the Division of General Surgery, Department of Surgery, Queen's University, Kingston, Ont. (Deghan Manshadi, Robertson, Zevin); the Faculty of Medicine, University of Ottawa, Ottawa, Ont. (Dehghan); and the Department of Anesthesiology and Perioperative Medicine, Queen's University, Kingston, Ont. (Reimer).

Competing interests: Boris Zevin reports fellowship support from Ethicon and a research grant from Medtronic. No other competing interests were declared.

Contributors: S. Deghan Manshadi, D. Robertson and B. Zevin designed the study. S. Deghan Manshadi and K. Dehghan acquired the data, which S. Deghan Manshadi and C. Reimer analyzed. S. Deghan Manshadi, D. Robertson and B. Zevin wrote the manuscript, which all authors critically revised. All authors gave final approval of the article to be published.

Content licence: This is an Open Access article distributed in accordance with the terms of the Creative Commons Attribution (CC BYNC-ND 4.0) licence, which permits use, distribution and reproduction in any medium, provided that the original publication is properly cited, the use is noncommercial (i.e., research or educational use), and no modifications or adaptations are made. See: https://creativecommons. org/licenses/by-nc-nd/4.0/.

Funding: None declared. 


\section{References}

1. Bennett JM, Mehta S, Rhodes M. Surgery for morbid obesity. Postgrad Med 7 2007;83:8-15.

2. Mauro M, Taylor V, Wharton S, et al. Barriers to obesity treatment. Eur F Intern Med 2008;19:173-80.

3. Report card on access to obesity treatment for adults in Canada 2019. Edmonton: Obesity Canada; 2019. Available: https://obesitycanada. ca/wp-content/uploads/2019/04/OC-Report-Card-2019-Eng-F-web. pdf (accessed 2021 Dec. 25).

4. Navaneelan T, Janz T. Adjusting the scales: obesity in the Canadian population after correcting for respondent bias. Health at a Glance series. Cat no 82-624-X. Ottawa: Statistics Canada; 2014.

5. Health Fact Sheet: Overweight and obese adults, 2018. Ottawa: Statistics Canada; 2019 June 25.

6. Sjöström L, Lindroos AK, Peltonen M, et al.; Swedish Obese Subjects Study Scientific Group. Lifestyle, diabetes, and cardiovascular risk factors 10 years after bariatric surgery. $N$ Engl 7 Med 2004;351: 2683-93.

7. Christou N. Laparoscopic bariatric surgery can be performed safely in secondary health care centres with a dedicated service corridor to an affiliated tertiary health care centre. Can 7 Surg 2013;56:E68-74.

8. Zevin B, Aggarwal R, Grantcharov TP. Simulation-based training and learning curves in laparoscopic Roux-en-Y gastric bypass. $\mathrm{Br} \mathcal{F}$ Surg 2012;99:887-95.

9. Barber D, Morkem R, Dalgarno N, et al. A retrospective cohort study examining patients eligible for bariatric surgery and those being referred in south eastern Ontario. Can Fam Physician 2021;67: e31-40.

10. Doumouras AG, Albacete S, Mann A, et al. A longitudinal analysis of wait times for bariatric surgery in a publicly funded, regionalized bariatric care system. Obes Surg 2020;30:961-8.

11. Kumar SB, Hamilton BC, Wood SG, et al. Is laparoscopic sleeve gastrectomy safer than laparoscopic gastric bypass? A comparison of 30-day complications using the MBSAQIP data registry. Surg Obes Relat Dis 2018;14:264-9.
12. Morton JM, Winegar D, Blackstone R, et al. Is ambulatory laparoscopic Roux-en-Y gastric bypass associated with higher adverse events? Ann Surg 2014;259:286-92.

13. Inaba CS, Koh CY, Sujatha-Bhaskar S, et al. How safe is same-day discharge after laparoscopic sleeve gastrectomy? Surg Obes Relat Dis 2018;14:1448-53.

14. Inaba CS, Koh CY, Sujatha-Bhaskar S, et al. Same-day discharge after laparoscopic Roux-en-Y gastric bypass: an analysis of the Metabolic and Bariatric Surgery Accreditation and Quality Improvement Program Database. 7 Am Coll Surg 2018;226:868-73.

15. Oh J, Perlas A, Lau J, et al. Functional outcome and costeffectiveness of outpatient vs inpatient care for complex hind-foot and ankle surgery. A retrospective cohort study. 7 Clin Anesth 2016; 35:20-5.

16. Purger DA, Pendharkar AV, Ho AL, et al. Outpatient vs inpatient anterior cervical discectomy and fusion: a population-level analysis of outcomes and cost. Neurosurgery 2018;82:454-64.

17. Slowey MJ, Coddington CC. Microsurgical tubal anastomoses performed as an outpatient procedure by minilaparotomy are less expensive and as safe as those performed as an inpatient procedure. Fertil Steril 1998;69:492-5.

18. Xu R, Batter TH, Basta S, et al. Improvements in ureteroscopy efficiency when performed at an ambulatory surgery center. Urol Pract 2019;6:289-93.

19. Urman RD, Sarin P, Mitani A, et al. Presence of anesthesia resident trainees in day surgery unit has mixed effects on operating room efficiency measures. Ochsner 7 2012;12:25-9.

20. Chang SH, Freeman NLB, Lee JA, et al. Early major complications after bariatric surgery in the USA, 2003-2014: a systematic review and meta-analysis. Obes Rev 2018;19:529-37.

21. Ladak F, Dang JT, Switzer NJ, et al. Rates of reoperation and nonoperative intervention within 30 days of bariatric surgery. Surg Obes Relat Dis 2019;15:431-40.

22. Doumouras AG, Saleh F, Anvari S, et al. Mastery in bariatric surgery: the long-term surgeon learning curve of Roux-en-Y gastric bypass. Ann Surg 2018;267:489-94. 